Article

\title{
Studies on the Oxidation Behavior and Microstructural Evolution of Two Nb-Modified HR3C Austenitic Steels under Pure Water Vapor at $650{ }^{\circ} \mathrm{C}$
}

\author{
Jinlong Wang ${ }^{1}\left(\mathbb{D}\right.$, Bo Meng $^{1}$, Jintao Lu ${ }^{2, *}$, Yongli Zhou ${ }^{2}$, Dongxu Yang ${ }^{3}$, Qunchang Wang ${ }^{1}$, \\ Minghui Chen $1, * \mathbb{B}$ and Fuhui Wang ${ }^{1}$ \\ 1 Shenyang National Laboratory for Materials Science, Northeastern University, Shenyang 110819, China; \\ wangjinlong@mail.neu.edu.cn (J.W.); 1910132@stu.neu.edu.cn (B.M.); qcwang@mail.neu.edu.cn (Q.W.); \\ fhwang@mail.neu.edu.cn (F.W.) \\ 2 State Key Laboratory of Coal-Based Clean Energy, Xi'an Thermal Power Research Institute Co., Ltd., \\ Xi'an 710032, China; zhouyongli@tpri.com.cn \\ 3 Liaoning Non-Ferrous Geological Exploration and Research Institute Co., Ltd., Shenyang 110819, China; \\ lanbeier0216@163.com \\ * Correspondence: lujintao@tpri.com.cn (J.L.); mhchen@mail.neu.edu.cn (M.C.); Tel.: +86-24-23904856 (M.C.); \\ Fax: +86-24-23893624 (M.C.)
}

Received: 7 November 2020; Accepted: 26 November 2020; Published: 29 November 2020

\begin{abstract}
The steam oxidation behavior of three heterogeneous HR3C alloys was investigated at $650{ }^{\circ} \mathrm{C}$ comparatively. After a long-term oxidation process for $1000 \mathrm{~h}$, the results demonstrated that the commercial HR3C alloy already exhibited a high oxidation resistance. However, the spallation resistance of the oxide scale was low during the initial oxidation period. The addition of a moderate amount of $\mathrm{Nb}$ into the alloy (1\#HR3C) increased the oxidation resistance of the alloy. In addition, the improvement of the microstructural stability was substantially influenced by solid solution strengthening and fine grain strengthening. However, the addition of excessive $\mathrm{Nb}$ could significantly affect the growth model of the oxide scale and negatively affect the oxidation performance and microstructural evolution of the alloy (2\#HR3C).
\end{abstract}

Keywords: austenitic stainless steel; steam oxidation; oxidation behavior; microstructural evolution

\section{Introduction}

In power plants, the energy efficiency is proportional to the steam temperature and pressure, which hastens the initiation and development of ultra-supercritical (USC) power plants [1,2]. USC refers to the temperature and pressure of the working fluid (here, water) in the boiler. When the temperature of the fluid exceeds $593{ }^{\circ} \mathrm{C}$ or the pressure surpasses $22.1 \mathrm{MPa}$, it is called USC [3]. A USC power plant has the advantages of low coal consumption and adequate environmental protection. As a result, USC power plants are attracting worldwide attention.

As the temperature and pressure of the working fluid increase, the service environment for the boiler heating components, which include the water-cooled wall, superheater, reheater, and economizer, becomes more aggressive and harsher [4-7]. To ensure safe application, these heating components should have superior creep strength, excellent thermal strength, high temperature corrosion, and oxidation resistance [8]. As a type of commercial austenitic stainless steel, HR3C has been widely used as materials for critical components in power plant boilers $[9,10]$ such as superheaters [11] and reheaters [12,13]. HR3C is modified from TP310 via the addition of strong carbide/nitride-forming elements such as $\mathrm{Nb}$ and $\mathrm{N}$ to increase the creep strength $[14,15]$. Moreover, the oxidation resistance of HR3C is substantially higher than those of the conventional coarse-grained austenitic stainless steels 
such as TP304H [16]. This is because the extent of Fe-rich scale formation is minimized and thus a Cr-rich layer predominates. Currently, most studies on HR3C have focused on high temperature creep resistance or corrosion resistance $[15,17-20]$. Few studies have investigated the changes on both sides.

With increasing service time, cracking or spalling of the oxide scale that formed on the substrate is inevitable. Young et al. reported [21,22] that the oxide scales would crack when Fe-17Cr steel was oxidized in $\mathrm{Ar}-5 \mathrm{O}_{2}-20 \mathrm{H}_{2} \mathrm{O}$ for $48 \mathrm{~h}$ at $700{ }^{\circ} \mathrm{C}$. Therefore, the structures of the substrate alloys will change, which will cause mechanical property degradation and reduce the service life [23]. The preparation of coatings on the surface and the use of composition modification in alloying elements are both convenient strategies for increasing the stability of the alloy structure. However, investigations have reported severe problems regarding element interdiffusion between the coating and the underlying alloy, which have deleterious effects on the mechanical properties, especially when used in USC power plants for thousands of hours [23]. Thus, modification of the alloying elements in the composition is the preferred approach, and a series of studies have been conducted [24-26]. Brady reported [24] that niobium was found to be beneficial for alumina scale formation in newly developed creep-resistant austenitic stainless steels. Nguyen et al. reported $[25,26]$ that cerium and manganese improved the resistance to high temperature oxidation of $\mathrm{Fe}-20 \mathrm{Cr}-20 \mathrm{Ni}$ in dry $\mathrm{CO}_{2}$. Cai et al. [27] reported that an increased amount of $\mathrm{N}$ in the solid solution could strengthen the matrix and suppress the coarsening of $\mathrm{M}_{23} \mathrm{C}_{6}$ precipitates. Yuan et al. [28] reported that the addition of Co could increase the rupture strength by lowering the stacking fault energy of the matrix. The addition of a suitable amount of $\mathrm{Nb}$ into $\mathrm{HR} 3 \mathrm{C}$ austenitic stainless steel can significantly increase the strength of the steel, which reduces the dispersions of $\mathrm{Cr}_{23} \mathrm{C}_{6}$ compounds, and then the solid solution of $\mathrm{Nb}$ in the case of the low carbon equivalent of $\mathrm{M}_{23} \mathrm{C}_{6}$ [29]. However, the mechanism and synergistic effect of element modification on the oxidation behavior and mechanical proprieties remain unclear.

In this study, niobium and other elements were modified in commercial HR3C with the primary objective of increasing the mechanical stability and oxidation resistance. However, unexpected effects of niobium on the degradation of the scale and the oxidation behavior were observed. As a result, comparative studies on the oxidation behavior and microstructural evolutions of a commercial HR3C alloy and two types of modified HR3C were conducted at $650^{\circ} \mathrm{C}$ under steam oxidation for $1000 \mathrm{~h}$. The effects of niobium on the oxidation behavior and the mechanical properties are discussed.

\section{Materials and Methods}

In total, three materials were exposed: a commercial HR3C alloy and two modified HR3C alloys. These three types of HR3C steels were designed and produced by the Xi'an Thermal Power Research Institute. The compositions of the HR3C alloys were analyzed using an ICP (inductive coupled plasma) spectrometer and are presented in Table 1. For convenience, the modified HR3C steels were denoted as 1\#HR3C and 2\#HR3C. These HR3C ingots were prepared by VIM (vacuum induction melting) and homogenized at $1200{ }^{\circ} \mathrm{C}$ to achieve an excellent alloy balance, then were hot-forged and rolled at $1170{ }^{\circ} \mathrm{C}$. The specimens for these experiments were cuboids with nominal dimensions of $10 \mathrm{~mm} \times$ $10 \mathrm{~mm} \times 2 \mathrm{~mm}$. They were ground consecutively with \#120, \#240, \#400, and \#600 SiC papers and degreased using an ultrasonic cleaner in acetone and ethanol.

Table 1. Compositions of the three groups of HR3C alloys detected by inductive coupled plasma (ICP) (wt.\%).

\begin{tabular}{cccccccccccc}
\hline Alloy. & $\mathbf{N i}$ & $\mathbf{C r}$ & $\mathbf{M n}$ & $\mathbf{N b}$ & $\mathbf{S i}$ & $\mathbf{N}$ & $\mathbf{C}$ & $\mathbf{B}$ & $\mathbf{P}$ & $\mathbf{C o}$ & $\mathbf{F e}$ \\
\hline Nominal HR3C & 20.40 & 24.65 & 1.07 & 0.43 & 0.47 & 0.23 & 0.07 & - & 0.019 & - & Bal. \\
Commercial & 20.08 & 23.79 & 1.01 & 0.41 & 0.47 & 0.21 & 0.05 & - & 0.020 & - & Bal. \\
HR3C & & & & & & & & & \\
1\#-HR3C & 18.91 & 23.3 & 0.03 & 0.59 & 0.44 & 0.16 & 0.20 & 0.002 & 0.027 & 4.65 & Bal. \\
2\#-HR3C & 19.43 & 20.7 & 0.03 & 2.93 & 0.28 & 0.13 & 0.13 & 0.002 & 0.018 & 4.74 & Bal. \\
\hline
\end{tabular}


As shown in Figure 1, the steam oxidation experiment was conducted in a newly built water heat and loop facility for $1000 \mathrm{~h}$. The water heat and loop facilities equipment used for oxidation testing were cooperatively designed by Northeastern University (Shenyang, China) and the Xi'an Thermal Power Research Institute (Xi'an, China). A circulating water system that was coupled with a constant heating source provided a continuous supply of water vapor. The operating parameter of the pressure furnace reached $650{ }^{\circ} \mathrm{C}$ and $0.1 \mathrm{MPa}$. Synthetic air with high purity $\mathrm{Ar}(99.99 \%$ pure) was used as a carrier gas in the water supply system. The inlet conductivity of the water was measured as $0.1 \mathrm{~cm} / \mathrm{s}$ and the oxygen concentration was less than $6 \mathrm{ppm}$ in the deoxygenated water. Four parallel specimens were all fixed on a Ni-Cr frame and moved into when heated up to $650^{\circ} \mathrm{C}$. After periods of isothermal oxidation, the specimens were taken from the heating furnace. As the specimens were cooled down to room temperature, an electronic balance $(0.01 \mathrm{mg}$ precision, Sartorius BP211D) was used to record the mass change of the samples.

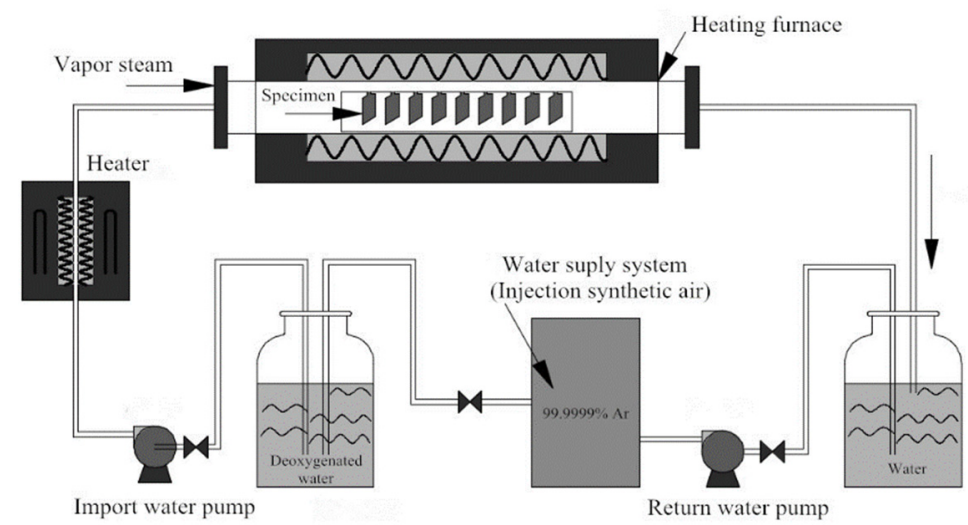

Figure 1. Schematic diagram of the water heating and loop facilities that were used for the steam oxidation experiments.

The compositions of alloys were confirmed by an inductively coupled plasma emission spectrometer (ICP, ICAP Q, ThermoFisher, Waltham, MA, USA). Phase constituents were characterized by XRD (X'Pert PRO, PANalytical Co., Almelo, Holland, $\mathrm{Cu}$ Ka radiation at $40 \mathrm{kV}$ ). The obtained $x$-ray diffraction patterns were recorded in the $2 \theta$ range of $10-90^{\circ}$, and a step-scanning mode was employed with a step size of $0.02^{\circ}$. To be noticed, grazing incidence x-ray diffraction (GI-XRD) at incident beam angle of $0.5^{\circ}$ was used to analyze the phase constituents of thin scales. The morphologies and microstructures of oxidized samples were characterized by scanning electron microscope (SEM, Inspect F 50, EFI Co., Hillsboro, OR, USA) coupled with an energy dispersive spectrometer (EDS, X-Max, Oxford instruments Co., Oxford, UK) and a transmission electron microscope (TEM, JEM-2100F, JEOL, Tokyo, Japan). Unless otherwise specified, a secondary electron mode was used to examine the surface morphology, and a back-scattered electron mode was used to obtain cross-sectional images of the samples via SEM. During the TEM process, the bright field STEM mode was used to capture the microstructure morphologies and selected area electron diffraction and an energy dispersive spectrometer were used to obtain the phase constituents. Photographs of the metallographic structure after corrosion etching were captured by a digital microscope (B011; Shenzhen Supereyes Technology, Shenzhen, China). The variation in the Vickers hardness with the exposure time was examined using a Micro Hardness apparatus (Blueheler Micrometer5114 Mitutoyo Co., Kanagawa, Japan) with a load of $500 \mathrm{~g}$ for $30 \mathrm{~s}$. 


\section{Results}

\subsection{Oxidation Kinetics}

Figure 2 shows the oxidation kinetics at $650{ }^{\circ} \mathrm{C}$ of the three groups of alloys. All specimens showed a fast initial oxidation stage, followed by a slower steady stage. However, differences were readily observed among the three groups. The commercial HR3C alloy increased the most in weight within the initial $50 \mathrm{~h}$ of oxidation. After that period (from 50 to $400 \mathrm{~h}$ oxidation), the mass gain slowly decreased as the oxidation test proceeded to a minimum mass gain of $0.316 \mathrm{mg} / \mathrm{cm}^{2}$. Multiple spallations occurred on the oxide scale that had formed on the alloy substrate, which resulted in severe fluctuations in mass. Compared with the mass gain of the commercial HR3C alloy, the mass gain of the modified 1\#HR3C alloy exhibited a similar but more stable kinetic curve for $1000 \mathrm{~h}$ oxidation testing. It showed the most stable mass change trend among the three groups. It strictly obeyed a sub-parabolic law within the first $500 \mathrm{~h}$ and reached a maximum mass gain of $0.449 \mathrm{mg} / \mathrm{cm}^{2}$. After that, a minor decrease in weight was observed. It is inferred that slight spallation subsequently occurred. The 2\#HR3C alloy exhibited a sharp mass decrease in the initial $50 \mathrm{~h}$ and showed the highest growth rate of oxides, while unstable oxidation occurred on it according to an overview of its oxidation kinetic results. After the whole oxidation test for $1000 \mathrm{~h}$, the mass gain of the commercial HR3C and 1\#HR3C alloys was only one-third of the 2\#HR3C mass gain.

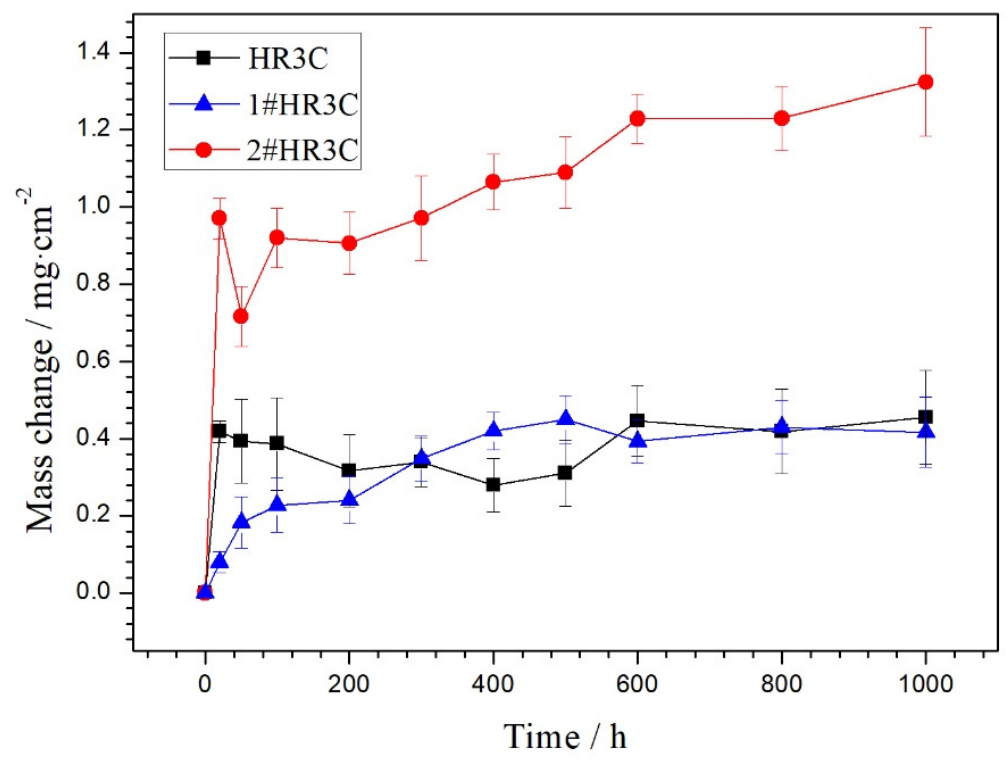

Figure 2. Steam oxidation kinetics of the three groups of $\mathrm{HR} 3 \mathrm{C}$ alloys at $650{ }^{\circ} \mathrm{C}$ for $1000 \mathrm{~h}$.

\subsection{Phase Constituents}

GI-XRD patterns of the commercial HR3C and modified 1\#HR3C and 2\#HR3C alloys after oxidation at $650{ }^{\circ} \mathrm{C}$ for $1000 \mathrm{~h}$ are shown in Figure 3. Since the oxide scale was extremely thin, the strongest peaks still corresponded to the metallic phase (austenite $\gamma$ phase). The oxide scales that formed on the commercial HR3C and 1\#HR3C alloys were almost completely composed of the same oxides, except that moderate amounts of $\mathrm{Nb}$ oxides were observed within the scale. The oxide scale was composed mainly of $\mathrm{Cr}_{2} \mathrm{O}_{3}$ for the HR3C and 1\#HR3C alloys and mainly of $\mathrm{Fe}_{2} \mathrm{O}_{3}$ for the 2\#HR3C alloy. The $\mathrm{Nb}_{2} \mathrm{O}_{5}$ peaks were stronger for $2 \# \mathrm{HR} 3 \mathrm{C}$ than for the others. 


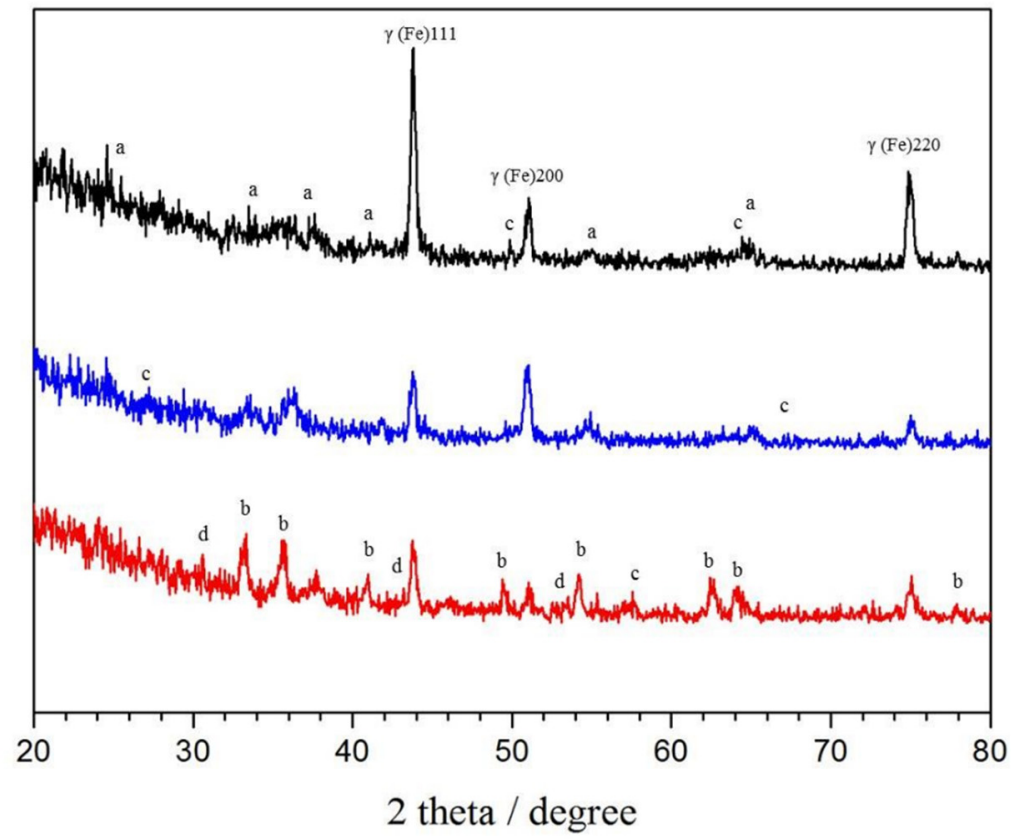

Figure 3. X-ray diffraction (XRD) patterns of the three groups of HR3C alloys after exposure to steam oxidation at $650{ }^{\circ} \mathrm{C}$ for $1000 \mathrm{~h}\left(\mathrm{a}: \mathrm{Cr}_{2} \mathrm{O}_{3}, \mathrm{~b}: \mathrm{Fe}_{2} \mathrm{O}_{3}, \mathrm{c}: \mathrm{Nb}_{2} \mathrm{O}_{5}\right.$, and d: $\mathrm{FeCr}_{2} \mathrm{O}_{4}$ ).

\subsection{Microstructural Analysis}

Figure 4 shows the surface microstructure morphologies of the HR3C, 1\#HR3C, and 2\#HR3C alloys after oxidation at $650{ }^{\circ} \mathrm{C}$ for $1000 \mathrm{~h}$. As shown in Figure $4 \mathrm{~A}$, the oxide scale that formed on the HR3C alloy surface was flat and uniform. Many metal grooves remained after polishing and grinding, and they remained visible after $1000 \mathrm{~h}$ of oxidation; hence, the scale that formed on the surface of the alloy was extremely thin. Compared with the HR3C alloy, the modified 1\#HR3C alloy showed a similar surface morphology after oxidation at $650{ }^{\circ} \mathrm{C}$ for $1000 \mathrm{~h}$, as shown in Figure $4 \mathrm{~B}$. Combined with the XRD analysis and EDS results, a thin $\mathrm{Cr}_{2} \mathrm{O}_{3}$ scale was forming on the surface, while spallation pores were observed on the 1\#HR3C alloy. In addition, precipitates appeared on the surface of the 1\#HR3C alloy. An amplified image of these precipitates that was obtained via EDS showed that they were mainly composed of $\mathrm{Nb}$-rich phases and that cracks were generated within the niobium oxides. Compared to the commercial HR3C and 1\#HR3C alloys, the modified 2\#HR3C alloy exhibited different surface morphologies and phase components. The oxide scale was mostly flat with $\mathrm{Cr}_{2} \mathrm{O}_{3}$ - except for globular nodules of island-like oxides that had grown on the surface of the alloy. With the help of EDS analysis, these brighter convex oxides were determined to be $\mathrm{Fe}_{2} \mathrm{O}_{3}$. Relatively small and dark oxides of $\mathrm{Nb}$ were also observed in the amplified surface image. After comparison, it was inferred that the oxide scale was thicker than those that formed on the other groups, where no distinct grooves were observed. This was in accordance with the oxidation kinetics.

To investigate the transformation process of the HR3C alloys in detail, the surface morphologies after exposure to water vapor at $650{ }^{\circ} \mathrm{C}$ for $50 \mathrm{~h}$ are shown in Figure 5 . These showed similar morphological characteristics to the long-term oxidation results. Nevertheless, pores and slight spallation were observed on the surface of the commercial HR3C alloy after $50 \mathrm{~h}$ (amplified in Figure 5A), which showed a surface morphology that differed from that of the sample that had been exposed for longer. This might be due to the thickening of the oxide scale, as the locations of these defects became difficult to observe. Furthermore, bright niobium oxides were observed on the 1\#HR3C alloy in Figure 5B. For the 2\#HR3C alloy, the short-term results were similar to the long-term surface morphology results, except that the island-like oxides were fewer and much smaller. As shown in Figure 5C, the EDS results demonstrated that the oxides in the bulgy area were enriched with $\mathrm{Fe}$, while those in the flat area were enriched with $\mathrm{Cr}$ and a moderate amount of $\mathrm{Nb}$. Based on the amplified 
image, many cracks and spallation areas were identified on the scales, especially at the location where niobium oxides formed.

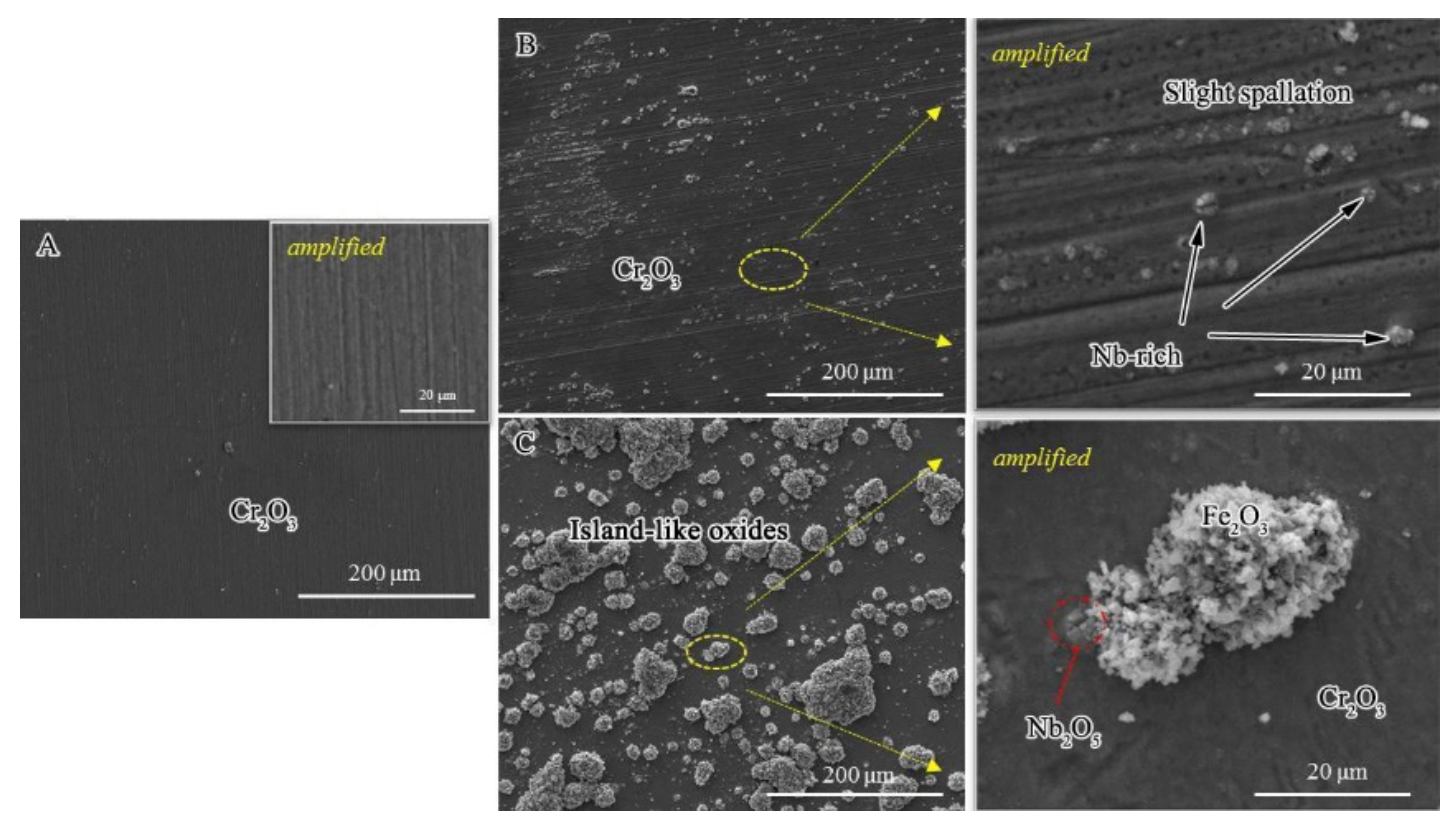

Figure 4. Surface morphologies of the alloys after oxidation in pure water vapor at $650{ }^{\circ} \mathrm{C}$ for $1000 \mathrm{~h}$ : (A) commercial HR3C alloy, (B) 1\#HR3C alloy, and (C) 2\#HR3C alloy.
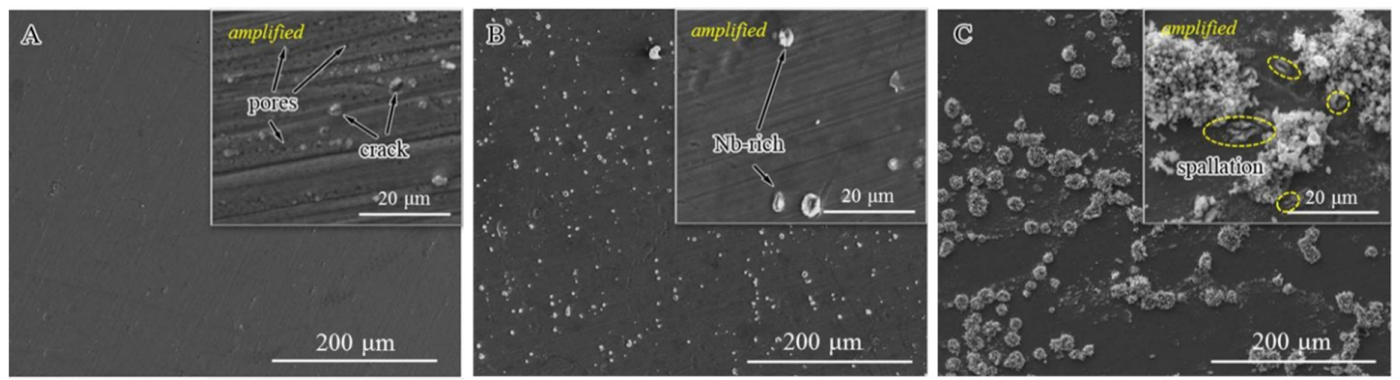

Figure 5. Surface morphologies of the alloys after oxidation in pure water vapor for the initial $50 \mathrm{~h}$ :

(A) commercial HR3C alloy, (B) 1\#HR3C alloy, and (C) 2\#HR3C alloy.

The cross-sectional microstructures of the commercial HR3C, 1\#HR3C, and 2\#HR3C alloys after oxidation at $650{ }^{\circ} \mathrm{C}$ for $1000 \mathrm{~h}$ are shown in Figure 6. Corresponding to the surface microstructure, the cross-sectional morphologies of the HR3C and 1\#HR3C alloys were relatively similar, and a thin layer of $\mathrm{Cr}_{2} \mathrm{O}_{3}$ scale was formed on the alloys. Slight spallation had occurred on 1\#HR3C after $1000 \mathrm{~h}$. For the 2\#HR3C alloy, the oxide scale had been divided into two layers: The outer grown layer was composed of a thin $\mathrm{Cr}_{2} \mathrm{O}_{3}$ layer and a convex $\mathrm{Fe}_{2} \mathrm{O}_{3}$ layer. The inner layer was rich in $\mathrm{Cr}$ and $\mathrm{Fe}$ (point b shown in Table 2), it might refer that serious internal oxidation of iron and chromia had occurred and $\mathrm{FeCr}_{2} \mathrm{O}_{4}$ spinel formed. Furthermore, cracking was observed between the two layers.

To investigate the microstructure of the oxide scale on the 2\#HR3C alloy after oxidation for $1000 \mathrm{~h}$ in detail, the TEM bright field image and EDS mapping results are shown in Figure 7. Judging from the integrity of the surface transmission sample adhesive and the dark oxides that participated on the surface morphologies, as shown in Figure 4, the sampling positions of the thin area after ion thinning process were concentrated on the surface of the sample. The formed oxides were brittle and breakages were observed between the two layers of oxide. Combined with the XRD and EDS mapping results, the oxides were divided into two regions: the shattered region of the oxides was rich in niobium, 
which reveals that $\mathrm{Nb}_{2} \mathrm{O}_{5}$ was especially enriched there. At other places outside the shattered region, no concentration of $\mathrm{Nb}$ was observed and these regions were composed mainly of Fe and $\mathrm{Cr}$ oxides.
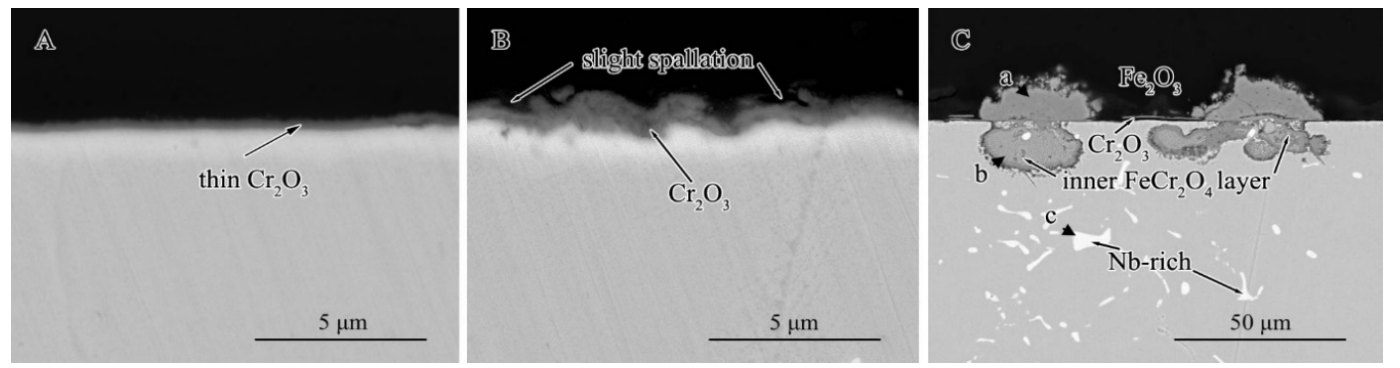

Figure 6. Cross-sectional morphologies of the three groups of alloys after oxidation in pure water vapor at $650{ }^{\circ} \mathrm{C}$ for $1000 \mathrm{~h}$ : (A) commercial HR3C alloy, (B) 1\#HR3C alloy, and (C) 2\#HR3C alloy.

Table 2. Chemical composition (wt.\%) measured (denoted in and Figure 6C) by energy dispersive spectrometer (EDS).

\begin{tabular}{cccccc}
\hline No. & $\mathbf{O}$ & $\mathbf{F e}$ & $\mathbf{C r}$ & $\mathbf{N b}$ & Bal \\
\hline $\mathrm{a}$ & 31.51 & 62.74 & 1.09 & & 2.20 \\
$\mathrm{~b}$ & 26.80 & 28.75 & 39.35 & & 5.1 \\
$\mathrm{c}$ & 2.15 & 1.09 & 0.84 & 95.32 & 0.6 \\
\hline
\end{tabular}
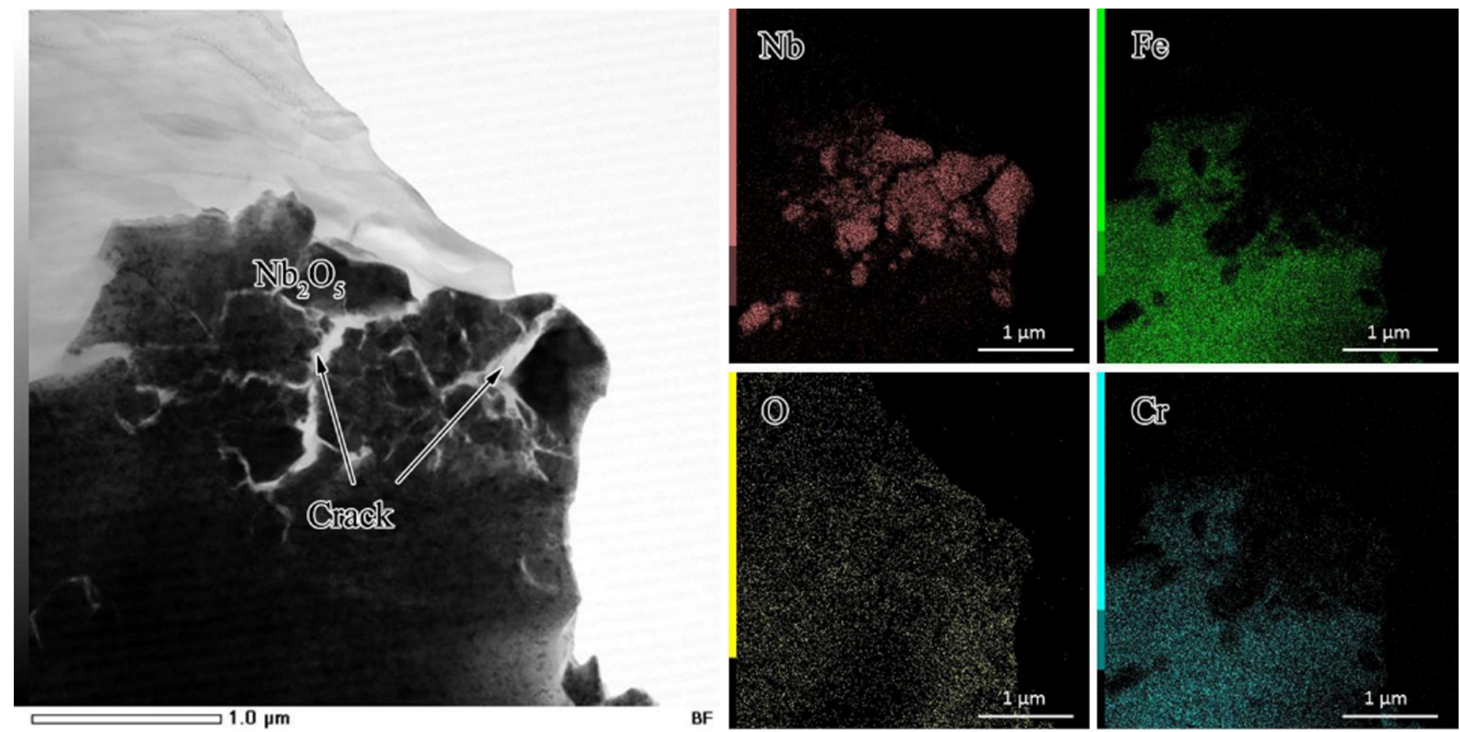

Figure 7. Transmission electron microscope (TEM) microstructures and elemental mappings of the oxide scale on the 2\#HR3C alloy after oxidation in pure water vapor at $650{ }^{\circ} \mathrm{C}$ for $1000 \mathrm{~h}$.

\subsection{Microstructural Evolution}

To investigate the effects of long-term oxidation on the mechanical properties of the alloys, the variations of the Vickers hardness of the three groups of alloys with the exposure time were examined, as shown in Figure 8. It is hypothesized that the mechanical properties of the alloys will be substantially affected by the high temperature oxidation, which is mainly due to the imbalance in the original substrate phases that are transformed into newly generated phases, which is caused by the consumption of scale-forming elements. The hardness of the modified 2\#HR3C alloy before the oxidation test was $13.98 \%$ lower than that of the commercial HR3C alloy when more than five times the amount of $\mathrm{Nb}$ element was added. In contrast, the microhardness of the 1\#HR3C alloy with a small 
amount of $\mathrm{Nb}$ was the highest among the three groups, namely, $227 \mathrm{Hv}$. The microhardness of the three alloys increased rapidly from $0 \sim 50 \mathrm{~h}$. However, the three groups of HR3C alloys showed different trends after that period. With the oxidation time increasing, the microhardness of the commercial HR3C alloy remained almost unchanged, while that of the 1\#HR3C alloy increased gradually. For the 2\#HR3C alloy, the microhardness initially increased and subsequently decreased with prolonged exposure time. After oxidation for $1000 \mathrm{~h}$, the hardness of the 1\#HR3C alloy increased from 227 to $270 \mathrm{Hv}$, which represents an increase of approximately 20\%, while the hardness of the 2\#HR3C alloy increased from 193 to $200 \mathrm{Hv}$, which represents an increase of only approximately 3.5\%.

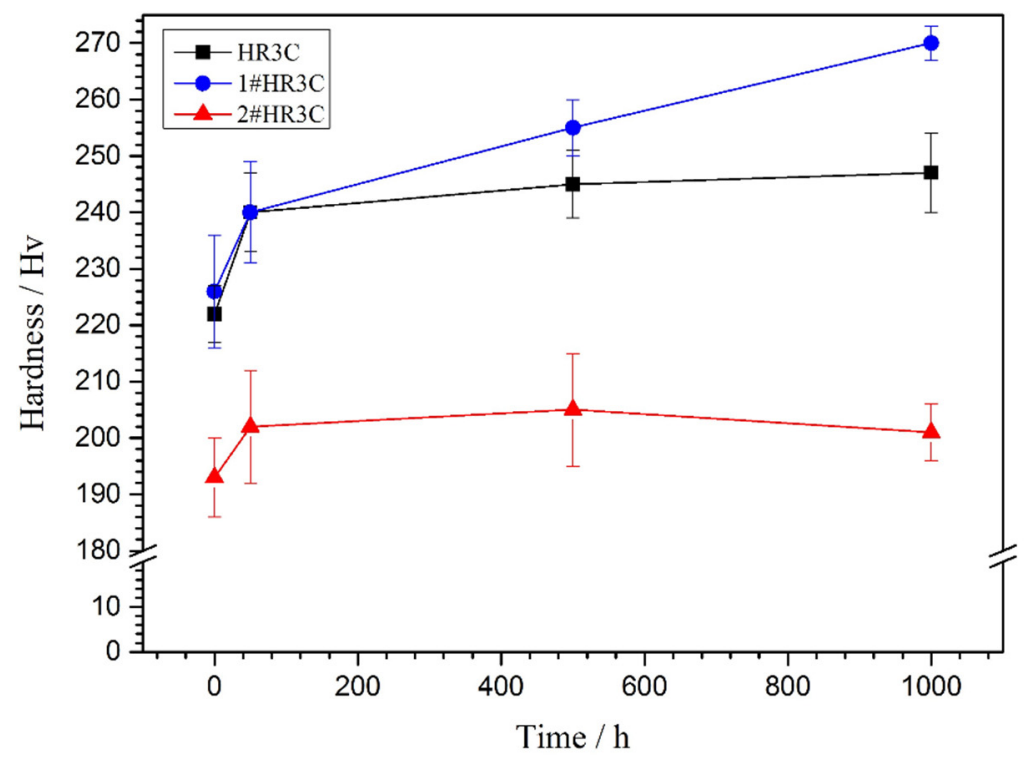

Figure 8. Variations of the microhardness of the three groups of HR3C alloys with the exposure time in a high-temperature water vapor environment at $650^{\circ} \mathrm{C}$.

Figure 9 shows corrosion etching images of the metallographic structure on the HR3C and modified HR3C alloys, which explain the changes in the average grain size of the three groups of alloys before and after oxidation at $650{ }^{\circ} \mathrm{C}$ for $500 \mathrm{~h}$. Prior to capturing the metallographic images, the oxide scales that formed on the surfaces of the specimens were slightly rubbed off. As $\mathrm{Nb}$ and $\mathrm{Co}$ solid solutions were added into the alloys, the overall grain sizes of the specimens had become much smaller than that of the commercial alloy. Hence, the original grain size of the HR3C alloy was the maximum, and that of the 2\#HR3C alloy was the minimum before the test. With the prolongation of the oxidation time, the grain size decreased, especially for the modified HR3C alloys. Compared with the commercial HR3C alloy, the grain size of the 1\#HR3C and 2\#HR3C alloys had decreased by almost 1.2 and 2.6 times, respectively. After long-term oxidation, the matrix structures of the modified HR3C alloys changed significantly. Many recrystallizations and second phases precipitated out, while the phase boundaries became smaller and the sizes became uniform.

In order to explore the mechanical properties of the 2\#HR3C alloy and their significant fluctuations in detail, the transmission high-resolution results of its microstructures after $1000 \mathrm{~h}$ were examined, as shown in Figure 10. Combined with the SAED (selected area electron diffraction) results, the $\gamma$-Fe was the main constituent phase. Furthermore, dark spot-like phases were observed in the substrate that corresponded to the $\mathrm{Cr}_{23} \mathrm{C}_{6}$, and the formation of these coarser phases are discussed in the next section. 

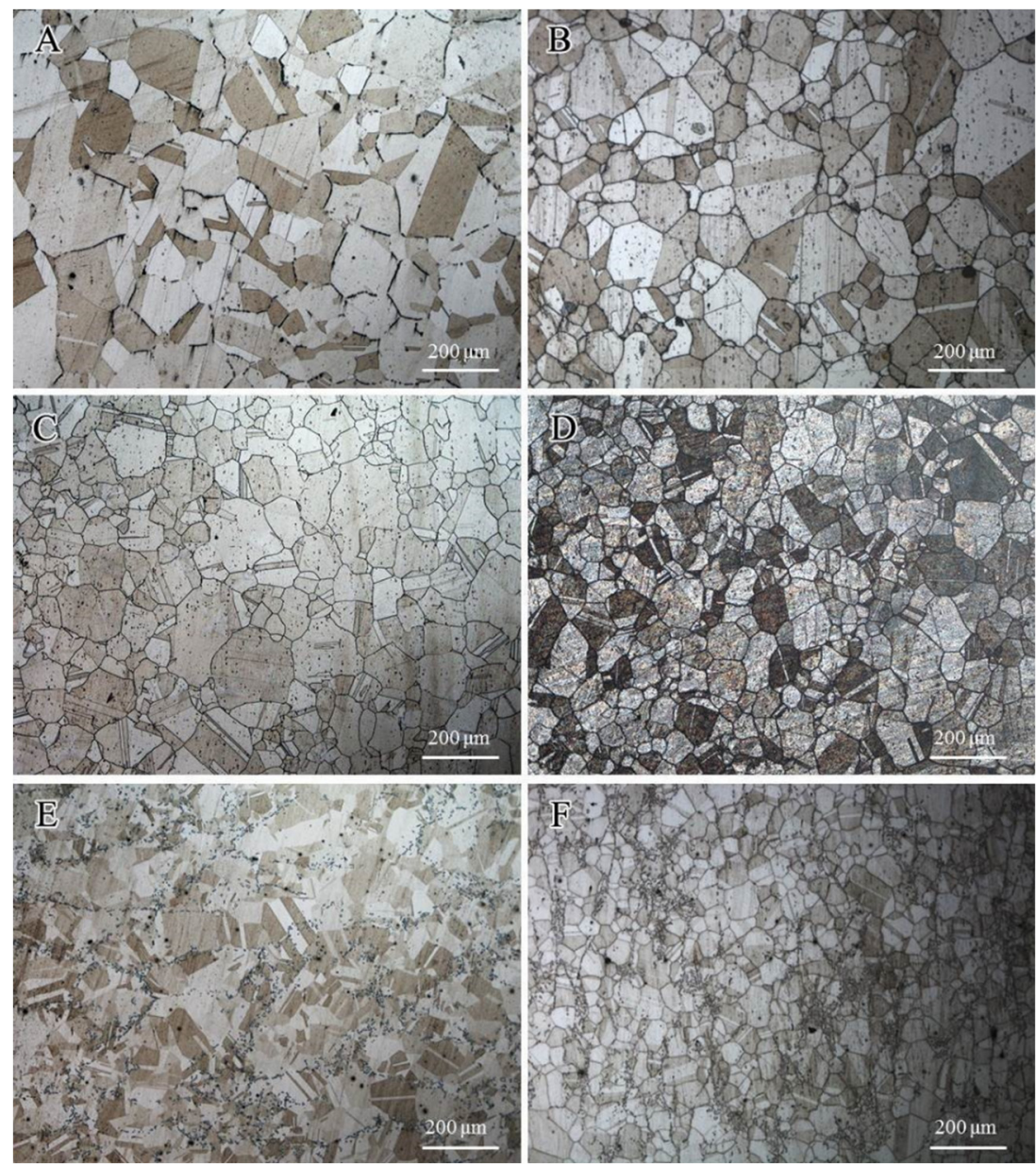

Figure 9. Optical micrographs of the three groups of HR3C alloys before and after steam oxidation at $650{ }^{\circ} \mathrm{C}$ for $0 \mathrm{~h}$ and $500 \mathrm{~h}$ : (A,B) commercial HR3C alloy, (C,D) 1\#HR3C alloy, and (E,F) 2\#HR3C alloy.
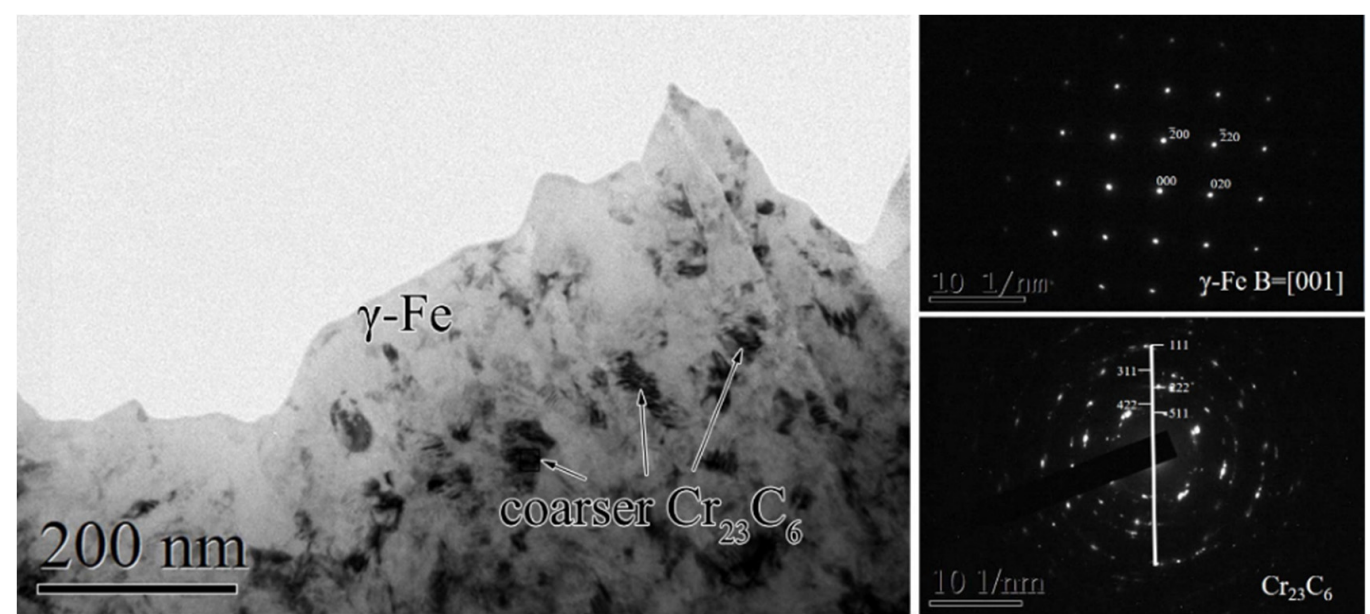

Figure 10. TEM microstructure of the 2\#HR3C alloy and its SAED patterns for $\gamma$-Fe and coarser $\mathrm{Cr}_{23} \mathrm{C}_{6}$ phases after exposure to pure water vapor at $650{ }^{\circ} \mathrm{C}$ for $1000 \mathrm{~h}$. 


\section{Discussion}

\subsection{Steam Oxidation Behavior of the HR3C Alloys}

Numerous studies have reported that the water vapor would accelerate the oxidation process of ferrite and austenite Fe-based alloys [30,31]. When oxidized in air at high temperature, the concentration of chromium (25 wt.\%) in HR3C steel is enough to sustain the formation of a protective scale [32,33]. In our previous study [34], there were at least three possible ways to cause the cracking of the chromia scales in a water vapor atmosphere. In short, the stress generated in the oxide scales and the decreased deformation of chromia during the oxidation process [16,35].

In our current study, the commercial HR3C alloy had suffered a certain degree of oxidation after a short exposure for $50-500 \mathrm{~h}$ at $650{ }^{\circ} \mathrm{C}$. As shown in Figures 2 and 4 , the mass change exhibited a slow decline, and slight spalling areas appeared on the surface of the commercial HR3C alloy. The failure mode and mechanism of $\mathrm{Cr}$ such as evaporation or spallation have been widely studied and reported $[9,36]$. It can be speculated that the rapid decomposition of the initially formed protective chromium oxide scale is due to the formation of volatile chromium-containing species within $50 \mathrm{~h}$. The volatilization of $\mathrm{Cr}$ occurs in the form of $\mathrm{CrO}_{3}(\mathrm{OH})_{2}$. The reaction not only requires the presence of water and oxygen in the reaction atmosphere, but temperature is also one of the most important factors [37]. In addition, as the minimum value of $\mathrm{P}_{\mathrm{H} 2 \mathrm{O}} \cdot \mathrm{P}_{\mathrm{O} 2}$ reached $3 / 4$ in this reaction furnace, the evaporation of $\mathrm{Cr}$-species can be ignored. Therefore, the main reason for the decrease in mass was spallation of the oxide scale within 50 to $350 \mathrm{~h}$, which might be related to the stress concentration in different directions during the thickening process of the oxide scales. When the oxidation process was prolonged to $1000 \mathrm{~h}$, minor spallation did not affect the oxidation resistance of the HR3C alloy at $650{ }^{\circ} \mathrm{C}$. A relatively dense layer of $\mathrm{Cr}_{2} \mathrm{O}_{3}$ scale grew on the surface of the substrate alloy, which was significantly related to the reason for the slow growth of the commercial HR3C alloy after $300 \mathrm{~h}$.

Compared with the commercial HR3C alloy, the modified 1\#HR3C alloy exhibited more stable oxidation resistance during the first $500 \mathrm{~h}$, and both the oxidation kinetics and the mass gain were the lowest within the three groups. Several studies showed that there were two strategies for improving the formation of high-quality oxide scale: (1) modifying the elemental components of the alloy to change the diffusion mode of $\mathrm{Cr} / \mathrm{O}$, and (2) grain refinement to reduce the critical $\mathrm{Cr}$ concentration for scale formation [38,39]. Mitsutoshi et al. [40] indicated that the critical Cr concentration in a wet atmosphere increased approximately 1.2 times higher than that in a dry environment. Compared with the commercial HR3C alloy, although the content of $\mathrm{Cr}$ in the 1\#H3RC alloy did not differ substantially, the modification of approximately $5 \%$ by weight of $\mathrm{Nb}, \mathrm{Co}$, and other elements changed its organizational structure. This will be discussed in detail in the next part. The other process is a substantial reduction in the grain size of the matrix, which utilizes selective oxidation of the alloy. Grain boundaries are important paths for short-range diffusion. For alloys with a high $\mathrm{Cr}$ content such as HR3C, grain refinement can significantly improve the selective oxidation of $\mathrm{Cr}$ on the alloy surface, and rapidly form a protective oxidation at high temperature. Figure 7 shows that the grain sizes of the modified HR3C alloys were much smaller than that of the commercial alloy, which was only approximately $200 \mu \mathrm{m}$. Otsuka et al. [41] quantitatively showed that the critical Cr concentration to form a dense scale had dropped approximately $20 \mathrm{wt}$.\% on an austenitic stainless steel with grains ranging from 110 to $20 \mu \mathrm{m}$ in a wet atmosphere. It can be speculated that the grain size reduction and minor element addition play an important role during the oxidation process. In addition, the $1 \# H R 3 C$ alloy showed thin and continuous microstructure morphologies in Figures 4 and 5 . The fine grain structure provided the diffusion channels and oxide nucleation sites for $\mathrm{Cr}$; thus, this alloy exhibited the best oxidation resistance among the three groups during the first $500 \mathrm{~h}$. However, minor trends of mass decrease and pores were observed in the kinetics and surface morphologies in the final process, which might due to the strong influence of long-term oxidation in the vapor environment for $1000 \mathrm{~h}$. After that, a $\mathrm{Cr}$ depletion region was formed beneath the oxide layer. Unexpected cracking and 
buckling finally exhibited as the substrates were insufficient for healing and sustaining the intact protective scale.

For the 2\#HR3C alloy, pores and nodule oxides were distinctly observed on the surface after oxidation. The number and size of the nodule oxides increased with the prolongation of the oxidation experiment, which corresponded well with the data of oxidation mass change in Figure 2. After longer exposure, the nodule oxides were expected to spread across the surface and form double-layered scales. These consisted mainly of less protective spinel and oxides of iron and niobium. In addition, many cracking and spallation areas were identified. The cracking and spallation of the protective chromium oxide scale led to weak interfacial adhesion. Thus, cracking was observed at the interface of the two oxide layers, and an internal oxidation process occurred. The cracks changed the oxidation process behavior of the HR3C from external to internal. As observed on the cross-sectional morphology in Figure 6, the spinel of $\mathrm{Cr}_{2} \mathrm{O}_{3}$ and iron precipitated in the metal through the inward diffusion of oxygen and the outward. Internal oxidation prevail was observed as the diffusion of $\mathrm{Cr}$ was predominantly affected by the oxygen permeability and the diffusion coefficient of chromium in the alloy. Compared with the commercial HR3C and 1\#HR3C alloys, the excessive content of $\mathrm{Nb}$ and its oxide precipitation in the modified 2\#HR3C alloy might be the main reason for the instability of early rapid oxidation and the transformation of the oxidation formation to an internal process. In addition, the development of spinel would be formed and controlled by oxygen diffusion along the grain boundaries.

\subsection{Effects of $\mathrm{Nb}$ Modification on the Steam Oxidation Behavior}

As a refractory element, niobium is often added to the elemental compositions of alloys for solid solution strengthening. The effects of $\mathrm{Nb}$ on the mechanical behaviors of alloys have been reported by many researchers [42,43]. Pint and Guo et al. [26,43-45] demonstrated that the addition of elements with large atomic radius such as $\mathrm{Y}, \mathrm{Zr}, \mathrm{Ce}, \mathrm{La}$, and $\mathrm{Hf}$ could significantly affect the oxidation behaviors of alumina-forming alloys, thus, improving the scale adhesion and oxidation performance. In our recent studies [46,47], the refractory element of Ta could also change the segregation state between grain boundaries, thereby resulting in a significant change in the formation mechanism of oxide scale, namely, a change in the diffusion mode of oxide scale from internal oxidation to external oxidation, similar to the reactive element. $\mathrm{Nb}$ oxides affect the stability of protective coatings such as chromium oxides.

In this study, the contents of $\mathrm{Nb}$ in the modified HR3C alloys were 0.59 and 2.36 by weight, which were approximately 0.37 and 4.81 times larger, respectively, than that of the commercial alloy. In addition to changing the main compositions of the oxides, it was found that the addition of $\mathrm{Nb}$ generated niobium oxides in the oxide scale. According to the value of the Gibbs free energy and its Ellingham-Richardson diagram under $650{ }^{\circ} \mathrm{C}$, niobium can form its oxide $\mathrm{Nb}_{2} \mathrm{O}_{5}$ in this process. Moreover, this was confirmed by the SEM/EDS and TEM results in Figures 4 and 5. Although the amount and area of $\mathrm{Nb}_{2} \mathrm{O}_{5}$ were not substantial compared with the main constituents of the oxides, it was found on the surface of the modified alloys immediately after $50 \mathrm{~h}$. The outward diffusion of $\mathrm{Nb}$ was through the grain boundaries in the alloy or oxides. As the atomic radius of $\mathrm{Nb}$ was large, the diffusion ability might be limited under $650{ }^{\circ} \mathrm{C}$ in the test. Therefore, there was no significant difference in the amount of $\mathrm{Nb}$ oxide between $50 \mathrm{~h}$ and $1000 \mathrm{~h}$. The effect of oxides that were formed by refractory elements on the oxidation behavior has frequently been considered in other studies such as Ta oxides [46,47], $\mathrm{W}$ oxides [48], and $\mathrm{Y}$ oxides [49]. For example, the creep lifetime could be significantly increased by co-adding $\mathrm{Nb}, \mathrm{Ti}$, and $\mathrm{V}$ together. However, this always had a negative effect on the oxidation behavior. The oxides of refractory elements were mostly unstable and prone to spalling or evaporation in a harsh high temperature environment. As shown in Figures 8 and 9, the amplified morphologies of the $\mathrm{Nb}$ oxides were fragmented and cracked. The oxides were less protective. This was because the oxides of $\mathrm{Nb}$ were brittle, and their lattice constant (crystal structure) and thermal expansion coefficients did not match those of $\mathrm{Fe}_{2} \mathrm{O}_{3}$ or $\mathrm{Cr}_{2} \mathrm{O}_{3}$, and they were likely to break up and crack at the scale-forming interface. Shen et al. [50] also reported that the breakaway of oxide layer might be caused by micro-cracks and channels. The voids or defects that were left by the 
cracking or peeling of $\mathrm{Nb}_{2} \mathrm{O}_{5}$ resulted in the subsequent precipitation and production of non-protective Fe oxides, which provided diffusion paths for the internal diffusion of $\mathrm{O}$. The oxidation performance depends on the diffusion process of $\mathrm{Cr}$ and $\mathrm{O}$. Usually, the diffusion rate $\mathrm{of}^{3+}$ is prone to be being affected by the vacancy concentration and temperature. The addition of $\mathrm{Nb}$ in $\mathrm{HR} 3 \mathrm{C}$ alloys might have a significant influence on the vacancy formation energy of $\mathrm{Cr}$, thereby affecting the external oxidation behavior of $\mathrm{Cr}$.

\subsection{Effects of Element Modification on the Mechanical Properties}

The original objective of adding $\mathrm{Nb}$ was to improve the mechanical properties of the HR3C alloy. The creep-resistance properties of HR3C alloys were prone to being affected by the precipitation behaviors during the isothermal aging and oxidation process. The precipitation hardening of nano-sized MC-type (with a cF-NaCl structure, $\mathrm{NbC}$ ) carbides substantially increased the creep resistance. In the optical micrographs of the three groups of alloys in Figure 9, several phase boundaries and dislocation structures were observed in the modified 1\# and 2\#HR3C alloys. It was speculated that the addition of $\mathrm{Nb}$ led to the substantial decrease in the grain size of the alloy. In addition to MC carbides, excessive $\mathrm{Nb}$ might lead to the formation of coarse $\mathrm{Fe}_{2} \mathrm{M}$-Laves phases, while less $\mathrm{Nb}$ leads to the formation of $\mathrm{Cr}_{23} \mathrm{C}_{6}$ [43]. The moderate amount of $\mathrm{Nb}$ in the 1\#HR3C alloy led to the highest microhardness among the three groups due to a large amount of second-phase precipitation. However, as shown in Figure 10, phases that dark void-like microstructures were observed in the 2\#HR3C alloy, which was identified as the primary $\mathrm{NbC}$ particles. Coarse harmful brittle phases such as $\mathrm{Cr}_{23} \mathrm{C}_{6}$ and $\sigma$-FeCr particles were always precipitated from the austenitic alloy after long-term aging at $600-900{ }^{\circ} \mathrm{C}$. Since these brittle phases act as a path for crack propagation at the grain boundaries, especially in a long-term SCW environment at high temperatures, the chain-like distribution of these brittle phases in the chain-like distribution causes a significant decrease in ductility and toughness. Intergranular corrosion was more inclined to happen as the $\mathrm{Cr}$-depletion area extends to a critical size in the substrate alloy [51,52]. In addition, any other harmful mechanical phases such as the $G$ phase $\left(\mathrm{Ni}_{16} \mathrm{Si}_{7} \mathrm{M}, \mathrm{M}=\mathrm{Nb} / \mathrm{Ti} / \mathrm{Zr}\right.$, Cf- $\mathrm{Mn}_{23} \mathrm{Th}_{6}$ type) and Laves phase $\left(\mathrm{Fe}_{2} \mathrm{M}, \mathrm{M}=\mathrm{Mo} / \mathrm{Nb}, \mathrm{hp}-\mathrm{MgZn} \mathrm{n}_{2}\right.$ type) $[53,54]$ would be precipitated and have a negative effect on the mechanical properties of $\mathrm{HR} 3 \mathrm{C}$ with a excessive modification of $\mathrm{Nb}$.

Figure 11 shows the relationship between the average grain size and hardness versus the oxidation time for the alloys. The grain size of the alloy was finer after oxidation, and the hardness changed substantially with the prolongation of the oxidation time. The hardness of the three alloys increased after $50 \mathrm{~h}$, which was mainly due to the change of $\mathrm{Cr}_{23} \mathrm{C}_{6}$ that was caused by oxidation and the precipitation of $\mathrm{MC}$ on the grain boundaries. Wen reported that $\mathrm{Nb}$ could preferentially interact with $\mathrm{C}$ to form $\mathrm{NbC}$ to partially replace $\mathrm{Cr}_{23} \mathrm{C}_{6}$. This trend was supported by the thermal calculation [43]. Lu et al. [35] argued that the $\mathrm{Nb} / \mathrm{C}$ ratio could affect the phase precipitation, however, the hardness changed substantially with the prolongation of the oxidation time. The hardness of the commercial and 1\#HR3C alloys remained almost unchanged after $500 \mathrm{~h}$ of exposure, whereas that of the 2\#HR3C alloys decreased. This was due mainly to the precipitation and exfoliation of the $\mathrm{Nb}$ and matrix phases, thereby resulting in significant degradation of the mechanical properties of the alloy. Thus, the modified amount of $\mathrm{Nb}$ significantly influenced the phase precipitation process in the HR3C alloy, in which a suitable $\mathrm{Nb}$ content would inhibit the precipitation of $\mathrm{Fe}_{2} \mathrm{Nb}$ and $\mathrm{Cr}_{23} \mathrm{C}_{6}$ effectively.

A moderate amount of Co was also added to the modified 1\# and 2\#HR3C alloys. It has been reported that Co substantially influences the stacking fault energy (SFE) in Ni-Co binary alloys, and therefore also affects the ability to form twins. It plays an important role in increasing the rupture strength by reducing SFE. Furthermore, the low SFE can increase the dislocation spreading width and the dislocation density and promote dislocation entanglement. This results in the increase in the driving force of recrystallization and, thus, increased likelihood of recrystallization. It was also found that the addition of $C$ and Co could play a beneficial role in the formation of the $\mathrm{M}_{23} \mathrm{C}_{6}$ phase, while the effects of $\mathrm{Mn}, \mathrm{N}$, and $\mathrm{Si}$ on the mechanical proprieties remained unclear. The effects of these elements must be further explored systematically in the HR3C alloy. 


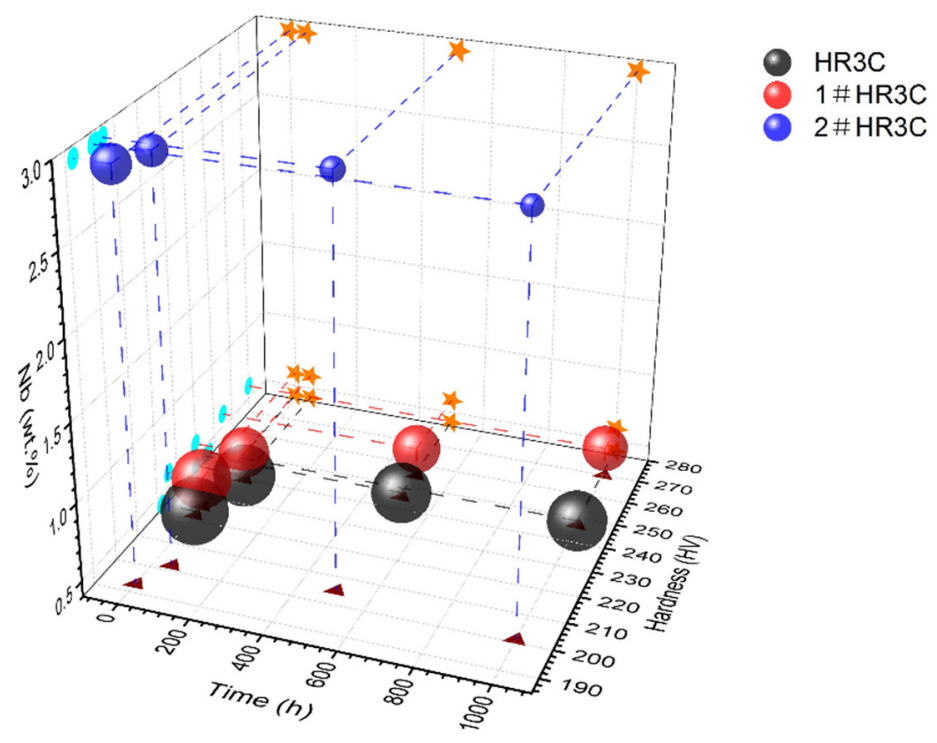

Figure 11. Variations of the average grain sizes of the three groups of HR3C alloys after steam oxidation with the exposure time, where the extent radius represents the grain size in the alloys.

\section{Conclusions}

Based on the commercial HR3C alloy, two modified alloys, namely, 1\#HR3C and 2\#HR3C, were prepared by adding alloying element $\mathrm{Co}$ while enhancing the content of $\mathrm{Nb}$. The oxidation behaviors in steam and the evolutions of the microstructure and hardness at $650{ }^{\circ} \mathrm{C}$ for $1000 \mathrm{~h}$ of the three alloys were investigated comparatively.

From the above study, the following conclusions can be drawn:

(1) The commercial HR3C alloy exhibited a certain extent oxidation resistance throughout the test. Slight spallation and the formation of pores were observed during the initial oxidation process. Its microstructure and hardness showed high stability under oxidation at $650{ }^{\circ} \mathrm{C}$.

(2) For the modified 1\#HR3C alloy, after increasing the $\mathrm{Nb}$ content by $37 \%$ and adding a moderate amount of $\mathrm{Co}$, its oxidation resistance was slightly enhanced compared to that of the commercial alloy. In addition, its microstructure was stable after oxidation for $1000 \mathrm{~h}$ at $650{ }^{\circ} \mathrm{C}$ and the hardness was even increased. Increasing alloying elements $\mathrm{Co}$ and $\mathrm{Nb}$ refined the alloy grains. Solid solution strengthening and fine-grain strengthening contributed to the increase in the hardness.

(3) For the modified 2\#HR3C alloy, the $\mathrm{Nb}$ content increased by 4.81 times compared to that of the commercial alloy. The oxidation rate was the highest among the three alloys and the oxide scale was more likely to spall off due to the formation of abundant but less-protective niobium oxide at the surface. Although its grain size was the finest, its microhardness was the lowest, irrespective of the fine-grain strengthening. After exposure at $650{ }^{\circ} \mathrm{C}$ for $500 \mathrm{~h}$, its hardness even began to decrease slightly.

Author Contributions: Conceptualization, J.W., B.M., J.L., and M.C.; Methodology, J.W., B.M., Y.Z., D.Y., and Q.W.; Investigation, J.W. and B.M.; Data curation, J.W., B.M., and J.L.; Writing-original draft preparation, J.W., and Q.W.; Writing-review and editing, J.L., B.M., D.Y., M.C., and F.W.; Visualization, J.W., Y.Z., and D.Y. All authors have read and agreed to the published version of the manuscript.

Funding: This project was financially supported by the Fundamental Research Funds for the Central Universities (no. N170203008), the Science and Technology Project of China Huaneng Group (HNKJ18-H16), the National Natural Science Foundation of China (nos. 51671053 and 51801021), and by the Ministry of Industry and Information Technology Project (no. MJ-2017-J-99).

Conflicts of Interest: The authors declare no conflict of interest. 


\section{References}

1. Surywanshi, G.D.; Pillai, B.B.K.; Patnaikuni, V.S.; Vooradi, R.; Anne, S.B. 4-E analyses of chemical looping combustion based subcritical, supercritical and ultra-supercritical coal-fired power plants. Energy Convers. Manag. 2019, 200, 112050. [CrossRef]

2. Rocha, D.H.; Silva, R.J. Exergoenvironmental analysis of a ultra-supercritical coal-fired power plant. J. Clean. Prod. 2019, 231, 671-682. [CrossRef]

3. Kritzer, P. Corrosion in high-temperature and supercritical water and aqueous solutions: A review. J. Supercrit. Fluids 2004, 29, 1-29. [CrossRef]

4. Xu, Y.-X.; Lu, J.-T.; Li, W.; Yang, Z.; Dang, Y.-Y.; Yang, X.W. Effect and role of alloyed yttrium on the fireside corrosion behaviour of Ni-Fe based alloys for $750{ }^{\circ} \mathrm{C}$ ultra-supercritical boiler applications. Corros. Sci. 2018, 143, 148-156. [CrossRef]

5. Abe, F.; Kutsumi, H.; Haruyama, H.; Okubo, H. Improvement of oxidation resistance of 9 mass $\%$ chromium steel for advanced-ultra supercritical power plant boilers by pre-oxidation treatment. Corros. Sci. 2017, 114, 1-9. [CrossRef]

6. Behnamian, Y.; Mostafaei, A.; Kohandehghan, A.; Amirkhiz, B.S.; Serate, D.; Sun, Y.; Liu, S.; Aghaie, E.; Zeng, Y.; Chmielus, M.; et al. A comparative study of oxide scales grown on stainless steel and nickel-based superalloys in ultra-high temperature supercritical water at $800{ }^{\circ} \mathrm{C}$. Corros. Sci. 2016, 106, 188-207. [CrossRef]

7. Li, Y.; Wang, S.; Sun, P.; Yang, J.; Tang, X.; Xu, D.; Guo, Y.; Yang, J.; Macdonald, D.D. Investigation on early formation and evolution of oxide scales on ferritic-martensitic steels in supercritical water. Corros. Sci. 2018, 135, 136-146. [CrossRef]

8. Sun, F.; Gu, Y.; Yan, J.; Zhong, Z.; Yuyama, M. Phenomenological and microstructural analysis of intermediate temperatures creep in a Ni-Fe-based alloy for advanced ultra-supercritical fossil power plants. Acta Mater. 2016, 102, 70-78. [CrossRef]

9. Viswanathan, R.; Sarver, J.; Tanzosh, J.M. Boiler Materials for Ultra-Supercritical Coal Power Plants-Steamside Oxidation. J. Mater. Eng. Perform. 2006, 15, 255-274. [CrossRef]

10. Zhu, Z.; Xu, H.; Khan, H.I.; Jiang, D.; Zhang, N. Effect of Exposure Temperature on Oxidation of Austenitic Steel HR3C in Supercritical Water. Oxid. Met. 2019, 91, 77-93. [CrossRef]

11. Pedraza, F.; Boulesteix, C.; Proy, M.; Lasanta, I.; de Miguel, T.; Illana, A.; Pérez, F.J. Behavior of Slurry Aluminized Austenitic Stainless Steels under Steam at 650 and $700{ }^{\circ}$ C. Oxid. Met. 2017, 87, $443-454$. [CrossRef]

12. Hussain, T.; Syed, A.U.; Simms, N.J. Fireside Corrosion of Superheater Materials in Coal/Biomass Co-fired Advanced Power Plants. Oxid. Met. 2013, 80, 529-540. [CrossRef]

13. Boissonnet, G.; Boulesteix, C.; Bonnet, G.; Balmain, J.; Pedraza, F. Thermal Transport Properties of New Coatings on Steels for Supercritical Steam Power Plants. Oxid. Met. 2017, 88, 191-202. [CrossRef]

14. Viswanathan, R.; Bakker, W. Materials for Ultrasupercritical Coal Power Plants-Boiler Materials: Part 1. J. Mater. Eng. Perform. 2001, 10, 81-95. [CrossRef]

15. Viswanathan, R.; Bakker, W. Materials for ultrasupercritical coal power plants-Turbine materials: Part II. J. Mater. Eng. Perform. 2001, 10, 96-101. [CrossRef]

16. Zengwu, Y.; Min, F.; Xuegang, W.; Xingeng, L. Effect of Shot Peening on the Oxidation Resistance of TP304H and HR3C Steels in Water Vapor. Oxid. Met. 2011, 77, 17-26. [CrossRef]

17. Sklenička, V.; Kuchařová, K.; Kvapilová, M.; Svoboda, M.; Král, P.; Dvořák, J. Creep properties of simulated heat-affected zone of HR3C austenitic steel. Mater. Charact. 2017, 128, 238-247. [CrossRef]

18. Zhang, J.; Rahman, Z.U.; Wang, X.; Wang, Z.; Li, P.; Wang, Y.; Bate, D.; Zhao, K.; Tan, H. Hot corrosion behaviors of TP347H and HR3C stainless steel with $\mathrm{KCl}$ deposit in oxy-biomass combustion. J. Environ. Manag. 2020, 263, 110411. [CrossRef]

19. Cao, J.; Gong, Y.; Yang, Z.-G.; Luo, X.-M.; Gu, F.-M.; Hu, Z.-F. Creep fracture behavior of dissimilar weld joints between T92 martensitic and HR3C austenitic steels. Int. J. Press. Vessel. Pip. 2011, 88, 94-98. [CrossRef]

20. Zhang, Z.; Hu, Z.; Tu, H.; Schmauder, S.; Wu, G. Microstructure evolution in HR3C austenitic steel during long-term creep at $650{ }^{\circ}$ C. Mater. Sci. Eng. A 2017, 681, 74-84. [CrossRef]

21. Othman, N.; Zhang, J.; Young, D. Water vapour effects on Fe-Cr Alloy Oxidation. Oxid. Met. 2010, 73, 337-352. [CrossRef] 
22. Othman, N.K.; Zhang, J.; Young, D.J. Temperature and water vapour effects on the cyclic oxidation behaviour of Fe-Cr alloys. Corros. Sci. 2010, 52, 2827-2836. [CrossRef]

23. Zhang, J.; Peng, X.; Young, D.J.; Wang, F. Nano-crystalline coating to improve cyclic oxidation resistance of 304 stainless steel. Surf. Coatings Technol. 2013, 217, 162-171. [CrossRef]

24. Brady, M.P.; Yamamoto, Y.; Santella, M.; Pint, B.A. Effects of minor alloy additions and oxidation temperature on protective alumina scale formation in creep-resistant austenitic stainless steels. Scr. Mater. 2007, 57, 1117-1120. [CrossRef]

25. Nguyen, T.; Zhang, J.; Young, D. Effects of cerium and manganese on corrosion of Fe-Cr and Fe-Cr-Ni alloys in $\mathrm{Ar}-20 \mathrm{CO}_{2}$ gas at $818^{\circ} \mathrm{C}$. Corros. Sci. 2013, 76, 231-242. [CrossRef]

26. Nguyen, T.; Zhang, J.; Young, D. Effects of cerium and manganese on corrosion of Fe-Cr and Fe-Cr-Ni alloys in $\mathrm{Ar}-20 \mathrm{CO}_{2}$ and $\mathrm{Ar}-20 \mathrm{CO}_{2}-20 \mathrm{H}_{2} \mathrm{O}$ gases at $650{ }^{\circ} \mathrm{C}$. Corros. Sci. 2015, 100, 448-465. [CrossRef]

27. Cai, B.; Kang, J.-H.; Hong, C.-W.; Kim, S.-J. Effects of $\mathrm{N}$ and $\mathrm{Cu}$ on the precipitation and the creep life of 316L austenitic stainless steel at $650^{\circ} \mathrm{C}$. Mater. Sci. Eng. A 2016, 662, 198-203. [CrossRef]

28. Yuan, Y.; Gu, Y.; Cui, C.; Osada, T.; Zhong, Z.; Tetsui, T.; Yokokawa, T.; Harada, H. Influence of Co content on stacking fault energy in Ni-Co base disk superalloys. J. Mater. Res. 2011, 26, 2833-2837. [CrossRef]

29. Bai, J.; Yuan, Y.; Zhang, P.; Yan, J. Effect of carbon on microstructure and mechanical properties of HR3C type heat resistant steels. Mater. Sci. Eng. A 2020, 784, 138943. [CrossRef]

30. Asteman, H.; Svensson, J.-E.; Norell, M.; Johansson, L.-G. Influence of Water Vapor and Flow Rate on the High-Temperature Oxidation of 304L; Effect of Chromium Oxide Hydroxide Evaporation. Oxid. Met. 2000, 54, 11-26. [CrossRef]

31. Wright, I.G.; Dooley, R.B. A review of the oxidation behaviour of structural alloys in steam. Int. Mater. Rev. 2010, 55, 129-167. [CrossRef]

32. Zieliński, A.; Dudziak, T.; Golański, G.; Gazdowicz, J.; Kofodziej, A. Effects of long-term ageing at high temperatures on oxide scale development and evolution of austenitic steels microstructure. Steel Res. Int. 2020, 91, 1900595. [CrossRef]

33. Wang, J.; Qiao, Y.; Dong, N.; Fang, X.; Quan, X.; Cui, Y.; Han, P. The Influence of Temperature on the Oxidation Mechanism in Air of HR3C and Aluminum-Containing 22-25Ni Austenitic Stainless Steels. Oxid. Met. 2018, 89, 713-730. [CrossRef]

34. Yuan, J.; Wang, W.; Zhang, H.; Zhu, L.; Zhu, S.; Wang, F. Investigation into the failure mechanism of chromia scale thermally grown on an austenitic stainless steel in pure steam. Corros. Sci. 2016, 109, 36-42. [CrossRef]

35. Saunders, S.; Monteiro, M.; Rizzo, F. The oxidation behaviour of metals and alloys at high temperatures in atmospheres containing water vapour: A review. Prog. Mater. Sci. 2008, 53, 775-837. [CrossRef]

36. Young, D.J. Effects of Water Vapour on the Oxidation of Chromia Formers. Mater. Sci. Forum 2008, 595-598, 1189-1197. [CrossRef]

37. Liao, Y.; Zhang, B.; Chen, M.; Feng, M.; Wang, J.; Zhu, S.; Wang, F. Self-healing metal-enamel composite coating and its protection for TiAl alloy against oxidation under thermal shock in $\mathrm{NaCl}$ solution. Corros. Sci. 2020, 167, 108526. [CrossRef]

38. Abe, F.; Araki, H.; Yoshida, H.; Okada, M.; Watanabe, R. The effect of grain size on the corrosion behaviour of inconel 600 in high-temperature steam. Corros. Sci. 1981, 21, 819-842. [CrossRef]

39. Peng, X.; Yan, J.; Zhou, Y.; Wang, F. Effect of grain refinement on the resistance of 304 stainless steel to breakaway oxidation in wet air. Acta Mater. 2005, 53, 5079-5088. [CrossRef]

40. Ueda, M.; Inoue, Y.; Ochiai, H.; Takeyama, M.; Maruyama, T. The Effect of Water Vapor on the Transition from Internal to External Oxidation of Austenitic Steels at 1073 K. Oxid. Met. 2012, 79, 485-494. [CrossRef]

41. Otsuka, N.; Shida, Y.; Fujikawa, H. Internal-external transition for the oxidation of Fe-Cr-Ni austenitic stainless steels in steam. Oxid. Met. 1989, 32, 13-45. [CrossRef]

42. Zaky, A.I.; El-Bitar, T. Effect of $\mathrm{Nb}$, Ti and cold deformation on microstructure and mechanical properties of austenitic stainless steels. Mater. Sci. Eng. A 2010, 527, 3662-3669. [CrossRef]

43. Wen, D.; Wang, Q.; Jiang, B.; Zhang, C.; Li, X.-N.; Chen, G.; Tang, R.; Zhang, R.; Dong, C.; Liaw, P. Developing fuel cladding $\mathrm{Fe}-25 \mathrm{Cr}-22 \mathrm{Ni}$ stainless steels with high microstructural stabilities via $\mathrm{Mo} / \mathrm{Nb} / \mathrm{Ti} / \mathrm{Ta} / \mathrm{W}$ alloying. Mater. Sci. Eng. A 2018, 719, 27-42. [CrossRef]

44. Guo, H.; Wang, D.; Peng, H.; Gong, S.; Xu, H. Effect of Sm, Gd, Yb, Sc and Nd as reactive elements on oxidation behaviour of $\beta-\mathrm{NiAl}$ at $1200{ }^{\circ} \mathrm{C}$. Corros. Sci. 2014, 78, 369-377. [CrossRef] 
45. Guo, H.; Li, D.; Zheng, L.; Gong, S.; Xu, H. Effect of co-doping of two reactive elements on alumina scale growth of $\beta$-NiAl at $1200{ }^{\circ} \mathrm{C}$. Corros. Sci. 2014, 88, 197-208. [CrossRef]

46. Wang, J.; Chen, M.; Yang, L.; Liu, L.; Zhu, S.; Wang, F.; Meng, G. The effect of yttrium addition on oxidation of a sputtered nanocrystalline coating with moderate amount of tantalum in composition. Appl. Surf. Sci. 2016, 366, 245-253. [CrossRef]

47. Wang, J.; Chen, M.; Zhu, S.; Wang, F. Ta effect on oxidation of a nickel-based single-crystal superalloy and its sputtered nanocrystalline coating at $900-1100{ }^{\circ} \mathrm{C}$. Appl. Surf. Sci. 2015, 345, 194-203. [CrossRef]

48. Safikhani, A.; Aminfard, M. Effect of $W$ and Ti addition on oxidation behavior and area-specific resistance of Fe-22-0.5Mn ferritic stainless steel for SOFCs interconnect. Int. J. Hydrogen Energy 2014, 39, 2286-2296. [CrossRef]

49. Telu, S.; Mitra, R.; Pabi, S.K. Effect of Y2O3 Addition on Oxidation Behavior of W-Cr Alloys. Met. Mater. Trans. A 2015, 46, 5909-5919. [CrossRef]

50. Shen, J.; Zhou, L.; Li, T. Effects of surface-applied ceria on the stability of thermally growing chromia scale of FeCr alloys and 310steel. J. Mater. Sci. 1998, 33, 5815-5819. [CrossRef]

51. Lai, J.K.L.; Wickens, A. Microstructural changes and variations in creep ductility of 3 casts of type 316 stainless steel. Acta Met. 1979, 27, 217-230. [CrossRef]

52. Xu, S.; Amirkhiz, B.S. Mechanical Properties of Fuel Cladding Candidate Alloys for Canadian SCWR Concept. JOM 2016, 68, 469-474. [CrossRef]

53. Sim, G.M.; Ahn, J.C.; Hong, S.C.; Lee, K.J.; Lee, K.S. Effect of Nb precipitate coarsening on the high temperature strength in $\mathrm{Nb}$ containing ferritic stainless steels. Mater. Sci. Eng. A 2005, 396, 159-165. [CrossRef]

54. Vodárek, V. Creep behaviour and microstructural evolution in AISI 316LN+Nb steels at $650{ }^{\circ} \mathrm{C}$. Mater. Sci. Eng. A 2011, 528, 4232-4238. [CrossRef]

Publisher's Note: MDPI stays neutral with regard to jurisdictional claims in published maps and institutional affiliations. 